Review Article

\title{
The plant cell cycle: Pre-Replication complex formation and controls
}

\author{
Juliana Nogueira Brasil ${ }^{1,3}$, Carinne N. Monteiro Costa ${ }^{1,4}$, Luiz Mors Cabral ${ }^{2}$, Paulo C. G. Ferreira ${ }^{1}$ and \\ Adriana S. Hemerly ${ }^{1}$ \\ ${ }^{1}$ Instituto de Bioquímica Médica Leopoldo de Meis, Universidade Federal do Rio de Janeiro, Rio de Janeiro, \\ RJ, Brazil. \\ ${ }^{2}$ Departamento de Biologia Celular e Molecular, Universidade Federal Fluminense, Niteroi, RJ, Brazil. \\ ${ }^{3}$ Centro Universitário Christus, Fortaleza, CE, Brazil. \\ ${ }^{4}$ Centro de Genômica e Biologia de Sistemas, Universidade Federal do Pará, Belém, PA, Brazil.
}

\begin{abstract}
The multiplication of cells in all living organisms requires a tight regulation of DNA replication. Several mechanisms take place to ensure that the DNA is replicated faithfully and just once per cell cycle in order to originate through mitoses two new daughter cells that contain exactly the same information from the previous one. A key control mechanism that occurs before cells enter $\mathrm{S}$ phase is the formation of a pre-replication complex (pre-RC) that is assembled at replication origins by the sequential association of the origin recognition complex, followed by Cdt1, Cdc6 and finally MCMs, licensing DNA to start replication. The identification of pre-RC members in all animal and plant species shows that this complex is conserved in eukaryotes and, more importantly, the differences between kingdoms might reflect their divergence in strategies on cell cycle regulation, as it must be integrated and adapted to the niche, ecosystem, and the organism peculiarities. Here, we provide an overview of the knowledge generated so far on the formation and the developmental controls of the pre-RC mechanism in plants, analyzing some particular aspects in comparison to other eukaryotes.
\end{abstract}

Keywords: Pre-replication complex, A. thaliana, cell cycle.

Received: May 01, 2016; Accepted: August 16, 2016.

\section{Introduction}

The eukaryotic cell cycle is a highly coordinated process, when a cell replicates its genome and divides it equally into two daughter cells. In order to assure that the genome will not only be correctly duplicated, but also correctly divided between daughter cells, a great number of control mechanisms take place during the cell cycle events. DNA replication is tightly monitored to ensure that the genome is replicated just once per cell cycle (Kearsey and Cotterill, 2003). This control relies on a mechanism that takes place before cells enter $\mathrm{S}$ phase and licenses cells for replication by selecting and activating origins of replication. The system is formed by the sequential recruitment of proteins to DNA replication origins, establishing the prereplication complex (pre-RC). It represents the key process in controlling chromosome replication.

The "permission to replicate" is directly connected to a number of internal and external features, like the avail-

Send correspondence to Adriana Hemerly. Instituto de Bioquímica Médica Leopoldo de Meis, Av. Carlos Chagas Filho, s/n, Centro de Ciências da Saúde, Bloco L ss29, Universidade Federal do Rio de Janeiro, 21941-590, Rio de Janeiro, RJ, Brazil. E-mail: hemerly@bioqmed.ufrj.br ability of nutrients, cell size, and others, in a way that cells can decide between entering $\mathrm{S}$ phase (thus initiating the process of cell division) or exit cell division cycle and start differentiating. The external controls regulating this step of the cell cycle are diverse among the multicellular eukaryotes, following their different developmental strategies, and interfering in the mechanisms regulating pre- $\mathrm{RC}$ activity. Therefore, this review uncovers the knowledge generated so far on the formation and the developmental controls of the pre-RC machinery in plants, analyzing some particular aspects in comparison to other eukaryotes.

\section{Plants as a model for studies on DNA replication controls.}

Plants are good models to study DNA replication controls, since they have various developmental and genome particularities. Plant development, compared to animals, is highly influenced by the environment in which they grow, suggesting that plants have evolved specific mechanisms that convey environmental signals to control cell division and ultimately plant growth. Plants, via post-embryonic organogenesis (Inzé and De Veylder, 2006), form new organs during their complete life span, and this contin- 
uous formation is tightly connected with the surrounding environment (Figure 1). Early in the development of the embryo, polarized forces establish the root and shoot meristems (Scheres, 2007). These meristematic cells and their descendants give rise to the various tissues and organs of a mature plant through the combined processes of cell division, cell expansion and cell differentiation. This ability depends on both the maintenance of proliferating cells in the meristems and the re-initiation of cell division in nondividing cells (Veylder et al., 2003). Considering that plant cells don't have the ability to move through the plant body, it becomes extremely important to coordinately control cell division and differentiation, so that a given cell can be present at its final place with its definitive fate (Brukhin and Morozova, 2011). In addition, higher plants adopt particular strategies of development ending up with a great variability of body architectures. This suggests that signaling controls regulating individual steps of the basic DNA replication machinery might also differ among plant species.

The plant kingdom is divided in two large groups: the monocots and the dicots. The best-studied members of each group are the dicot Arabidopsis thaliana and the monocot Oryza sativa. Although they share many characteristics, some important differences in their developmental plans and genome structure are present.

Different from other kingdoms, higher plants present extreme differences in its genome size (followed by phenotypical differences), with variations of more than 2,500 fold (Grime and Mowfforth, 1982). Allopolyploids, which are organisms that inherit their chromosomes from different species, are also common. Although chromosome number within species is usually constant, it can vary among plant species in a range that goes from $\mathrm{n}=2$ (in Haplopappus gracilis) to $\mathrm{n}=100$ (in Senecio biserratus). And, more interestingly, this number can also vary widely from generation to generation. Remarkably, it is also well known that controls coupling DNA replication with mitosis are quite flexible in plants. During development, plant cells often modify their classical cell cycle and undergo endoreduplication events that allow them to increase their ploidy level (Sugimoto-Shirasu and Roberts, 2003). However, the consequences of this modified cell cycle for plant development are not completely understood.

Taken together, all these characteristics indicate that plants developed a number of novel regulatory networks to integrate cell cycle progression, cell growth and differenti-

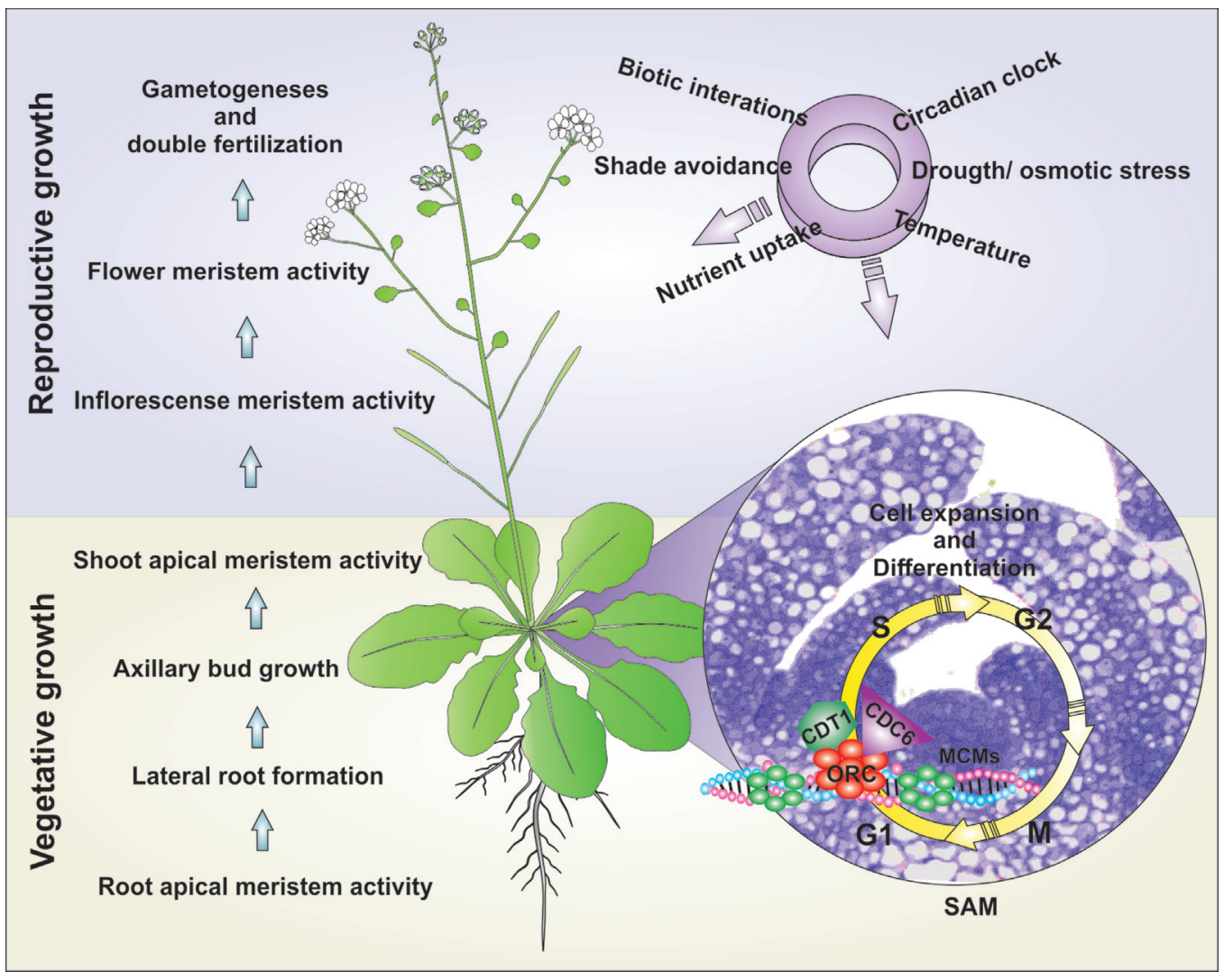

Figure 1 - Overview of cell cycle control modulation at meristems by endogenous and exogenous signals. Plants are continuously sensing the environment and modulating their development by adjusting cell division and differentiation rates at the different meristems. This means that every plant meristem might be sensing exogenous signals and integrating with genetic controls, which leads to changes in gene expression that will finally balance cell proliferation and differentiation rates, culminating with the correct plant form. The shoot apical meristem (SAM) is represented in the right panel. An important control of the G1 to S transition of the cycle is the pre-replication complex (pre-RC) that might be continuously regulated, although by some different mechanisms, along development. 
ation with endogenous and exogenous signaling, becoming unique organisms for the study of DNA replication and developmental abilities (Boniotti and Griffith, 2002). Thus, there has been an increasing interest in investigating the relationship between DNA replication controls and development in higher plants, and in the comparison with mechanisms employed by other eukaryotes. In this context, the first step that licenses DNA is one important crossroad when internal and environmental signals are integrated with cell division in order to trigger the developmental program in a flexible way.

\section{Licensing DNA replication: the assembly of the Plant pre-Replication Complex}

\section{Plant DNA Origins}

Cells must license DNA for replication by selecting and activating specific origins of replication. In eukaryotes, there is a large number of possible origins of replication, but only a group of these available origins is chosen to be used by different types of cells and in different moments during development. Origin activation is possibly the result of a multisource signaling pathways where positive and negative proliferating signals result in a response of the pre-RC machinery, in a way that once the origin activation starts cells are compromised with DNA replication.

The origins of replication consist of DNA sequences or chromatin marks (or both) that are recognized by proteins that bind to DNA, the Origin Recognition Complex (ORCs), and where other proteins will also bind to form the pre-RC (Cunningham and Berger, 2005).

In budding yeast, the recognition of origins by ORC seems to be unique because a consensus sequence has already been determined (the A-rich sequences named ACS) (Bell and Dutta, 2002; Nieduszynski et al., 2006). In contrast, it has been difficult to find clear consensus sequence in multicellular eukaryote organisms, due to their large genome size and fluctuation during differentiation and development (Aladjem, 2007; Hiratani et al., 2009). From Drosophila studies came the intriguing observation that the number of useful replication sites in a genome depends on other factors besides nucleotide sequence. In rapidly dividing nuclei of the Drosophila zygote there are many more initiation sites than in cultured cells, in a way that replication origins used during the early stages of embryogenesis are not used by mature cells (Blumenthal et al., 1974). Another possibility is that pre-RC interaction with the DNA might be related with DNA structure rather than sequence, as indicated in recent structural studies on archaeal orthologs of ORC interacting with the origin recognition box (Gaudier et al., 2007).

Experimental difficulties are the main constraint in the identification of a plant replication origin and in the characterization of its mechanism of recognition during DNA replication (Lee et al., 2009; Shultz et al., 2009;
Costas et al., 2011). Although little is known about DNA replication origins in plants, some features can be pointed as specific for plant origins in comparison to other eukaryotes (Bryant and Aves 2011; reviewed in Raynaud et al., 2014). It seems that origin consensus sequences are more GC-rich in metazoans and plants (Costas et al., 2011; Bass et al., 2014), in contrast with the AT-rich sequences in yeast (Mechali et al., 2013). Localization of these origins is preferentially near promoters of genes in metazoans (Cayrou et al., 2011). In A. thaliana, a study has sequenced and identified 1,500 putative genome-wide origins (Costas et al., 2011). That work revealed that $77.7 \%$ of origins were co-localized with gene units, preferentially towards their 5 ' end. Also, highly expressed genes tended to have more origins in regions immediately upstream or downstream (Costas et al., 2011). Replication origins from metazoans and yeast were found to be enriched with epigenetic marks (Dorn and Cook, 2011). In the same way, A. thaliana replication origins were found to be enriched with H3K4me3, H4K5ac and the variant histone H2A.Z (Costas et al., 2011). Also, it is possible that chromatin modification proteins are needed to specify and/or activate origins in $A$. thaliana, as (1) it has been shown that two HATs (histone acetyltransferases) are redundantly required for gametophyte development (Latrasse et al., 2008); and (2) origins of chromosome 4 are associated with H3Lys36ac (Lamesch et al., 2012). The same logic was found in animals: HATs are required to stabilize chromatin for ORC loading in Drosophila (Vorobyeva et al., 2013), and some chromatin modifier proteins are needed for the correct assembly or activation of pre-RC in mammals (Tardat et al., 2010) and yeast (Rizzardi et al., 2012).

\section{How is the pre-RC assembled in plants?}

A generalized eukaryotic licensing model based on yeast and animal systems support that origin selection begins at the transition from M to G1 phases of the cycle. At this moment, mitogenic signaling from the environment triggers the expression of Cyclin $\mathrm{D}$, a protein that interacts with CDKA (cyclin-dependent kinase A), forming the CDKA/CyclinD complex (Dresselhaus et al., 2006). This complex promotes phosphorylation of different targets, including the retinoblastoma protein $(\mathrm{RB})$, releasing the transcription factor E2F to promote expression of many pre-RC genes that bind to DNA replication origins at G1 phase (Figure 2). The first event in the formation of the pre- $\mathrm{RC}$ is the assembly of the ORC - a complex of six conserved subunits (ORC1-ORC6) to replication origins (Bell, 2002). After ORC assembly, other members of the pre-RC use $\mathrm{ORC}$ as a landing platform, to which they bind. The recruitment of CDC6 by ORC is the next step in pre-RC assembly, followed by the recruitment of CDT1 (Bell and Dutta, 2002). In addition, CDC6 and CDT1 proteins act synergistically to load a complex formed by six proteins - the MCM complex (MCM2-7; Mini Chromosome Maintenance). 


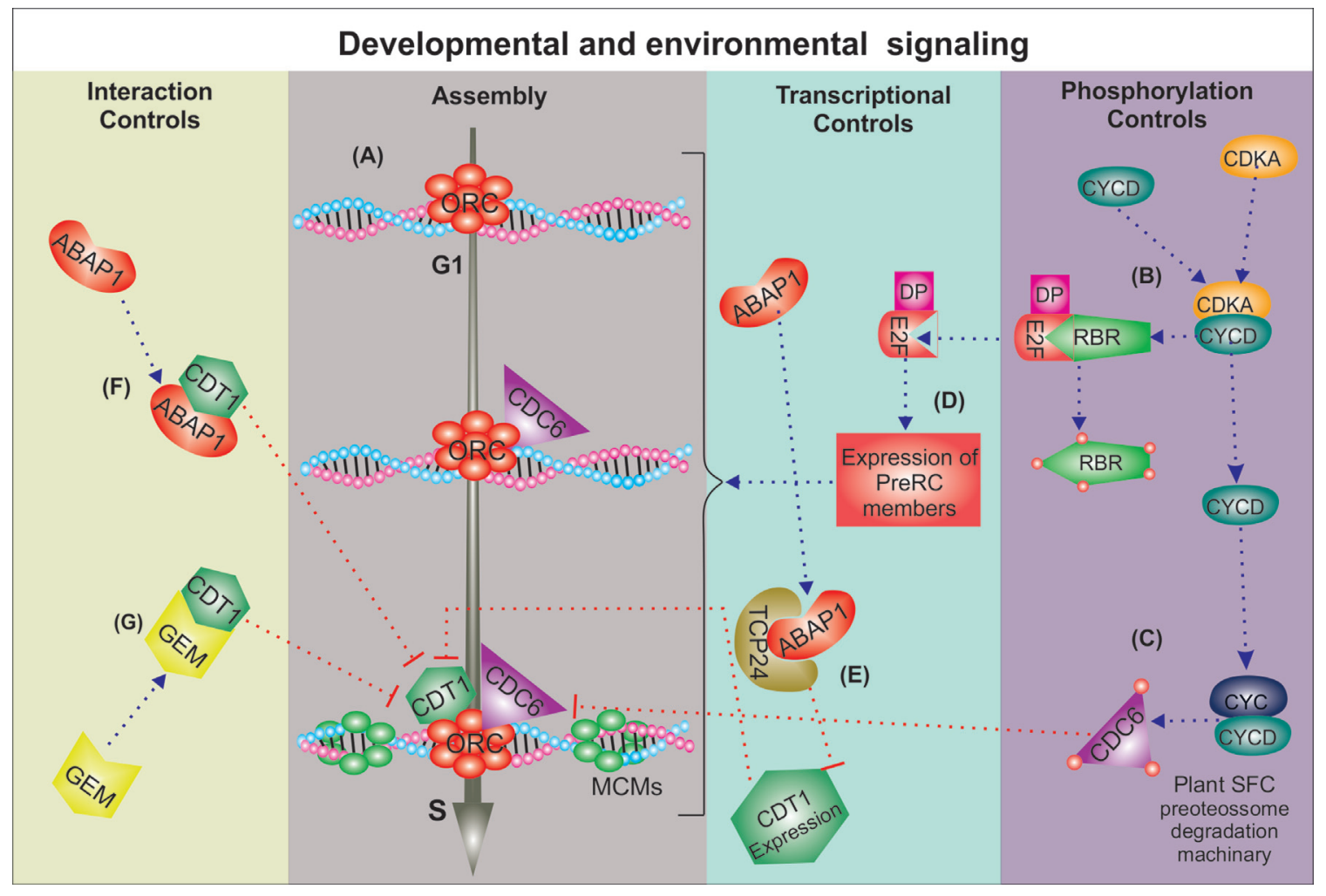

Figure 2 - Hypothetical model of pre-RC formation and regulation in plants. (A) Pre-replication complex (Pre-RC) assembly, activation and prevention of DNA re-replication is regulated by three major levels of controls that act in a coordinated way, connecting cell cycle progression with endogenous and exogenous (environmental) signaling. Protein phosphorylation by CDK/cyclin regulates different steps of DNA replication licensing: (B) first, they phosphorylate retinoblastoma protein, releasing E2F/DP to (D) activate transcription of pre-RC genes; (C) later, phosphorylation of members of the pre-RC promotes initiation of DNA replication and prevents DNA re-replication through nuclear exclusion and/or protein degradation. In addition to the transcriptional regulation by E2F/DP (D), pre-RC assembly is limited by repression of CDT1 transcription (E) by ABAP1/TCP24 (F), which also interacts directly with CDT1. (G) GEM also competes for binding to CDT1 making it less available for pre-RC loading.

MCM loading is the last event in the licensing mechanism. After that, origins are licensed to replicate and any site containing the MCM complex has the potential to form an active DNA replication fork (Masai et al., 2005) (Figure 2). The resulting complex loaded onto DNA, consisting of ORC1-6/CDC6/MCM2-7, is termed the pre-RC (for evolutionary aspects of pre-RC proteins through Archaea to eukaryotes see Bryant and Aves, 2011).

Pre-RC members can be identified by sequence homology in all genomes of higher plants available in public databases. A great number of members, were reported in eudicot A. thaliana (Gavin et al., 1995; Collinge et al., 2004; Masuda et al., 2004), and monocots like O. sativa (Kimura et al., 2000; Li et al., 2005; Mori et al., 2005; Shultz et al., 2007), and Zea mays (Sabelli et al., 1996, 1999; Bastida and Puigdomenech, 2002; Witmer, 2003; Dresselhaus et al., 2006) (Table 1). These features suggest that pre-RC function has been conserved in the course of eukaryote evolution, and support the belief of a high conservation of the replicative machinery among plants.

Nonetheless, some differences can be found in preRC members among plant species. Different from other eukaryotes studied so far, A. thaliana houses in its genome two homologs of ORC1,CDT1 and CDC6 (Ramos et al., 2001; Collinge et al., 2004; Masuda et al., 2004; DiazTrivino et al., 2005; Raynaud et al., 2005). Two OsCDT1 homologs are also present in the monocot rice (Shultz et al., 2007), but these gene duplications are not necessarily found in all plant species, suggesting that it is not a general feature in the plant kingdom (Table 1).

AtORC1 homologs, called ORC1a and ORCIb, are highly similar proteins, with around $90 \%$ of amino acid similarity. The N-terminal portion of AtORC1a and AtORClb contains a BAH (Bromo-Adjacent Homology) domain and a PHD (plant Homeodomain). BAH, associated with a PHD, has been implicated in linking DNA methylation, replication, and transcriptional regulation in mammals (Aasland et al., 1995; Callebaut et al., 1999). ORC1 has already been described as a transcriptional regulator in plants (Pak et al., 1997; Saitoh et al., 2002). The presence of the PHD exclusively in plant ORC1 genes among all other eukaryotes creates a very interesting observation, once this domain is responsible for specific binding to H3K4me3, both in vitro and in vivo (Sanchez and Gutierrez, 2009). Thus, it is possible that plant ORC1 genes are 


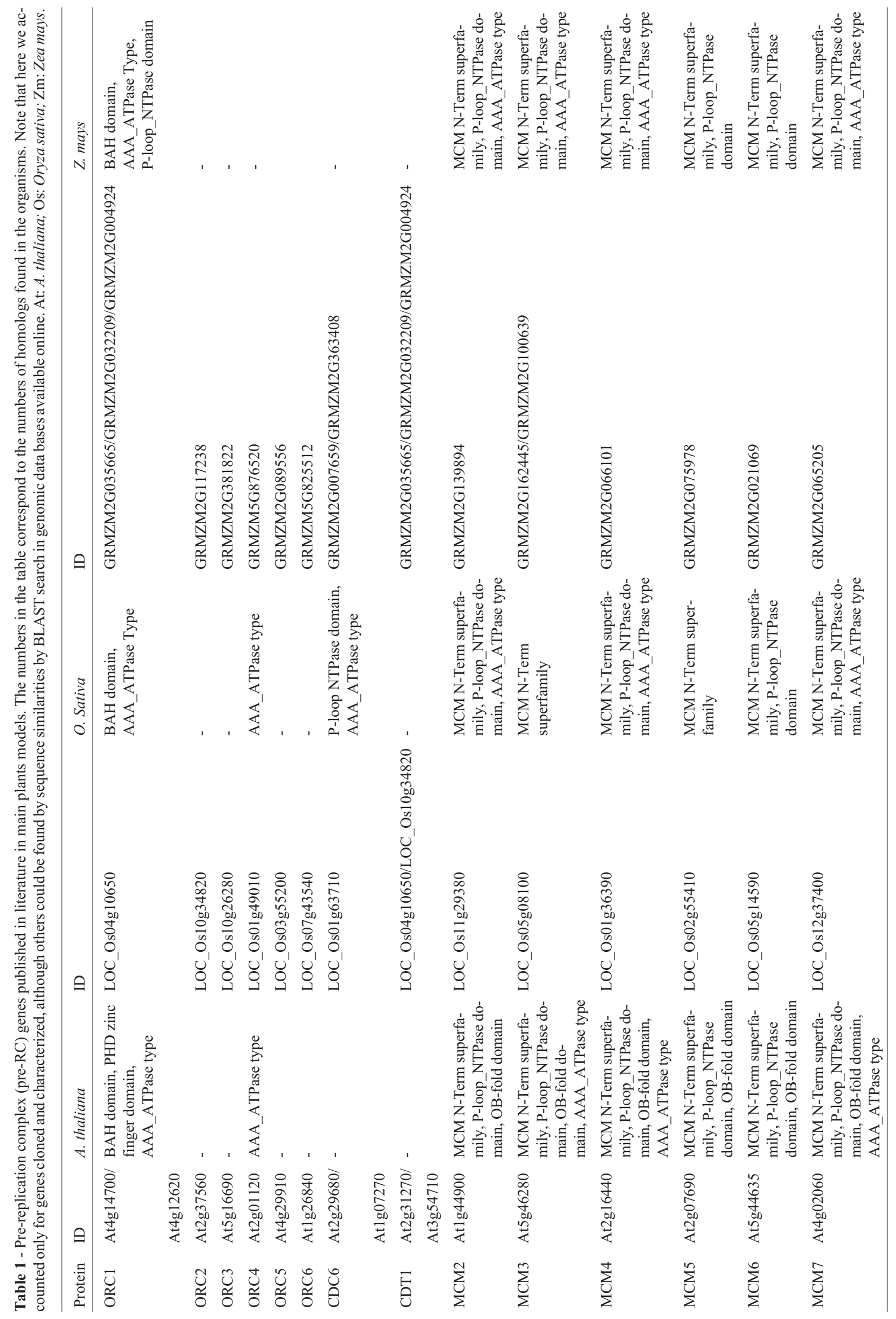


playing an important role on epigenetic regulation of cell cycle and plant development.

One copy of each $M C M$ gene has been identified in $A$. thaliana (Springer et al., 1995; Stevens et al., 2002; Masuda et al., 2004; Schreiber et al., 2006). Also, OsMCM2 encodes a functional homologue of the CDC19 fission yeast protein, able to rescue the wild-type phenotype in a mutant yeast for this gene, demonstrating how structurally close these proteins are (Cho et al., 2008). Finally, it has been shown that all six MCM cDNAs from pea (Pisum sativum) contain Zinc Finger motifs, ATPase consensus sequences like Walker A motif, Walker B motif or MCM signature, and an Arginine Finger motif (Tran et al., 2010). PSMCM2 contains a putative nuclear localization sequence, which is required for entering into the nucleus during G1/S-phase. PsMCM4 has an endoplasmic reticulum target and phosphorylation sites for CDKs. PsMCM5 contains the leucine zipper pattern consensus sequence, present in regulatory proteins including transcription factors $(\mathrm{Tu}-$ teja et al., 2011) (Table 1).

It is interesting to observe that the core DNA replication machinery components in plants are, by sequence homology, more similar to human than to budding yeast (Shultz et al., 2007). Moreover, some A. thaliana pre-RC members did not show any significant alignment with budding yeasts. This also confirms the observation that some cell cycle proteins that are present in humans, but not in yeast, are also present in A. thaliana and rice (Shultz et al., 2007).

\section{Regulation of pre-RC licensing by protein interactions, stability and distribution.}

Although mechanisms of cell division are conserved in eukaryotes, plants contain a larger number of cell cycle regulatory genes, such as 71 cyclin genes identified in $A$. thaliana, while only 15 were described in yeast and 23 in human (Van Leene et al., 2010). The understanding of how this complex machinery works involves revealing protein expression, interaction partners, targets and biological functions.

\section{Protein interactions between pre-RC members and beyond}

In order to investigate the arrangement of the pre-RC components within the complex, studies on the characterization of physical interactions among the $A$. thaliana, rice and maize ORC subunits were performed by yeast twohybrid and pull-down assays. Similarly, in these three plant species, ORC3 plays a central role in maintaining the complex associations; however, there are some intrinsic differences in ORC interaction patterns. In A. thaliana, protein interaction assays suggest a pre- $\mathrm{RC}$ architecture, in which AtORC 3 and AtORC2 are central elements in maintaining the complex associations (Masuda et al., 2004; Diaz-Tri- vino et al., 2005). A. thaliana has two ORC1 subunits, and AtORC3 interacts only with AtORC1b and not with AtORC1 a (Masuda et al., 2004; Diaz-Trivino et al., 2005). In rice, OsORC2 and OsORC 3 are also central pre-RC subunits, forming a core that binds OsORC5 and recruits OsORC4 (Tan et al., 2013). In maize, ZmORC3 can bind to ZmORC2, -4, -5, but ZmORC5 cannot bind to ZmORC2. Also, ZmORC1 has a weak interaction with the others (Witmer, 2003). In general, the interactions among plant pre-RC members are very similar to those found in humans (Dhar et al., 2001). Intrinsic differences in ORC interaction patterns among closely related species may suggest that: (1) they have little impact on assembly and function, or (2) they might hide evolutionary strategies in DNA replication initiation among species (Tan et al., 2013). Differences in expression profile among the pre- $\mathrm{RC}$ genes in the same plant species suggest that they might form different subcomplexes in the various plant tissues (discussed below). One interesting question that remains to be elucidated is whether the architecture of plant pre-RCs varies in different plant tissues and in response to developmental and environmental signals, acquiring specific roles depending on the developmental context.

Interactions of plant pre- $\mathrm{RC}$ members with proteins outside the complex have been identified by co-immunoprecipitation, pull-down and two-hybrid assays (Table 2). Nevertheless, few regulators of the plant DNA licensing machinery in response to cell differentiation and environmental signaling have been studied so far. Other than the cell cycle regulation by CDK-Cyclins, novel regulatory proteins have been described to control pre-RC assembly and/or function in plant development.

The Armadillo BTB Arabidopsis Protein 1 (ABAP1) is a plant-specific protein that binds directly to $\mathrm{ORCa} / \mathrm{b}$ and $\mathrm{CDT} 1 \mathrm{a} / \mathrm{b}$ in $A$. thaliana. ABAP1 negatively regulates the assembly of the pre-RC, which reduces DNA replication licensing and cell division rates (Masuda et al., 2008). ABAP1 could possibly prevent the assembly of a functional pre-RC complex by directly binding to members of pre-RC and/or by formation of a complex with TCP24, a transcription factor belonging to TCP class II that represses transcription of CDTla and CDT1b (Masuda et al., 2008). ABAP1 seems to participate in a negative feedback loop balancing mitotic DNA replication during leaf development (Figure 2).

Another pre-RC partner is Glabra2-Expression Modulator (GEM), that binds CDT1 a and CDT1b and is a candidate to play an important role controlling cell specification in A. thaliana (Caro et al., 2007). GEM promotes the differentiation and specification of root hair, probably by methylation of histone $\mathrm{H} 3 \mathrm{~K} 9$ to control expression of genes responsible for cell fate decisions in root (Caro et al., 2007) (Figure 2). 
Table 2 - Pre-replication complex (pre-RC) protein interactions observed in experimental analysis in A. thaliana. Techniques: 2HD: yeast two-hybrid PD: pull-down; IP: immuno-precipitation; TAP: tandem affinity purification.

\begin{tabular}{|c|c|c|c|}
\hline Gene 1 & Genes 2 & Techniques & Reference \\
\hline \multirow[t]{4}{*}{ ORC1a (AT4G14700) } & ABAP1 (AT5G13060) & 2HD, PD, IP & Masuda et al., 2008 \\
\hline & ABAP1 and TCP24 (AT1G30210)* & PD & Masuda et al., 2008 \\
\hline & ORC3 & PD & Masuda et al., 2008 \\
\hline & $\begin{array}{l}\text { DEA(D/H)-box (AT4G16630), EIF2 (AT5G20920), TIF3B1 } \\
\text { (AT5G27640) }\end{array}$ & TAP & Van Leene et al., 2010 \\
\hline \multirow[t]{2}{*}{ ORC1b (AT4G12620) } & ABAP1 & $2 \mathrm{HD}, \mathrm{PD}$ & Masuda et al., 2008 \\
\hline & ORC2 (AT2G37560), ORC5 (AT4G29910), ORC6 (AT5G42480) & PD & Diaz-Trivino et al., 2005 \\
\hline \multirow[t]{4}{*}{ ORC3 (AT5G16690) } & ORC2, ORC4, ORC5, ORC6 & PD & Diaz-Trivino et al., 2005 \\
\hline & ORC1A & $\mathrm{PD}$ & Masuda et al., 2008 \\
\hline & ABAP1 & 2HD, PD, IP & Masuda et al., 2008 \\
\hline & CYCb1;4 (AT2G26760) & TAP & Van Leene et al., 2010 \\
\hline \multirow[t]{3}{*}{ CDT1a (AT2G31270) } & ABAP1 & 2HD, PD, IP & Masuda et al., 2008 \\
\hline & GEM (AT2G22475) & $2 \mathrm{HD}, \mathrm{PD}$ & Caro et al., 2007 \\
\hline & CDKA, CYCD & $\mathrm{PD}$ & Castellano et al., 2004 \\
\hline \multirow[t]{3}{*}{ CDT1b (AT3G54710) } & ABAP1 & 2HD, PD & Masuda et al., 2008 \\
\hline & ABAP1 and TCP24* & $\mathrm{PD}$ & Masuda et al., 2008 \\
\hline & ARC6 & $\mathrm{BiFC}$ & Raynaud et al., 2005 \\
\hline \multirow[t]{3}{*}{ CDC6 (AT2G29680) } & CDC2 (AT3G48750) & $2 \mathrm{HD}$ & Pusch et al., 2012 \\
\hline & UBQ3 (AT5G03240) & TAP & Kim et al., 2013 \\
\hline & DUF936 (AT2G31920), AT4G28230, Histone H4, Cand1 (AT2G02560) & TAP & Van Leene et al., 2010 \\
\hline $\begin{array}{l}\text { MCM2, MCM } \\
\text { 3, MCM4, MCM5 }\end{array}$ & ETG1 (AT2G40550) & TAP & Van Leene et al., 2010 \\
\hline MCM6 (AT5G44635) & $\begin{array}{l}\text { ETG1 (AT2G40550), MCM2 (AT1G44900), ETG1, MCM4, MCM5, } \\
\text { MCM7, RPN7 (AT4g24820), NMD3 (AT2G03820), eIF-2B } \\
\text { (AT2G05830), EIF2 (AT5G20920), AT4G24820, SAMBA } \\
\text { (AT1G32310), PPR-like (AT1G05670), IMPA1 (AT3G06720) } \\
\text { AT2G05830, IMPa2 (AT4G16143), NAD7 (ATMG00510), AT-IMP } \\
\text { (AT3G06720) }\end{array}$ & TAP & Van Leene et al., 2010 \\
\hline \multirow[t]{2}{*}{ MCM7 (AT4G02060) } & GRF2 (AT1G78300) & TAP & Chang et al., 2009 \\
\hline & ETG1 (AT2G40550), CEL3 (AT1G71380), DUF936 (AT2G31920) & TAP & Van Leene et al., 2010 \\
\hline
\end{tabular}

*Triple Complex

\section{Protein stability and subcellular distribution}

The entrance into the cell cycle must be finely coordinated as it responds to diverse types of stimuli, including different growth factors, such as hormones and nutrients (Inzé and De Veylder, 2006; Takatsuka and Umeda, 2014). The majority of these regulators are connected to the cell cycle through the activity of cyclin-dependent kinases (CDKs), the main actors regulating progression through the cell cycle (Van Leene et al., 2010). CDKs work as a complex with cyclins for further phosphorylation of specific targets, in a general mechanism that involves: (1) cyclin synthesis and destruction, (2) CDK-cyclin assembly, (3) inhibitory and activating phosphorylation, and (4) the binding of inhibitory proteins (Inzé and De Veylder, 2006) (Figure 2).

Once the pre- $\mathrm{RC}$ is assembled in replication origins, a series of phosphorylation on specific targets regulates pre-
$\mathrm{RC}$ activation followed by prevention of re-replication. Several members of the pre-RC are reported to be CDK regulation targets, such as $\mathrm{CDC} 6, \mathrm{ORC} 1, \mathrm{ORC} 3$ and MCMs; and the resulting phosphorylation of these proteins drives them to different fates (Errico et al., 2010). In budding yeast, after assembly of pre-RC and licensing of DNA, $\mathrm{ScORC}$ (possibly ScORC2 and ScORC6) and CDC6 are phosphorylated by CDC7-DBF4 and the cyclin dependent kinase CDC28 (cdc2)-CLN1 (Jackson et al., 1993). This is followed by the displacement of CDC6 and MCM10 binding for activation of MCM 2-7 and initiation of DNA replication. CDC7/DBF4 kinases are as well important in regulating animal pre-RC, but they are not described in plants so far (Scofield et al., 2014).

To prevent re-replication, both in budding yeast and in animals, phosphorylated CDC6 becomes a target of the SCF proteasome machinery, and any remaining CDC6 is 
phosphorylated and inactivated by interaction with cyclins (Mimura et al., 2004). In A. thaliana, phosphorylation sites in CDC6 (Ramos et al., 2001) and MCMs (Dresselhaus et $a l ., 2006)$ were demonstrated, supporting a conserved regulation of the activation and prevention of re-replication steps in plants. To avoid re-replication, plants have as a key regulatory element the CDC6 dissociation from the pre-RC followed by its degradation, as well as the increase in CDC6 expression during S-phase and repression in G2 (Dambrauskas, 2003). During plant endoreplication, CDC6 is not degraded, and its overexpression induces rounds of endocycles (Bryant, 2011).

On the other hand, expression of most plant MCMs is greatly spread during the entire cycle (Springer et al., 2000; Holding and Springer, 2002; Huang et al., 2003; Cho et al., 2008). It seems that plant strategies to prevent extra rounds of DNA replication based on MCM regulation seem to be much more similar to animals than to budding yeast. MCM5 and MCM7 are the MCMs that topologically load onto DNA in plants (Shultz et al., 2009). MCM7 changes its dynamic of localization during the cell cycle, where it is highly associated with chromatin in phases G1, S and G2, and is dispersed in the cell only in the M phase (Shultz et al., 2009). This indicates that plants do not regulate origin licensing by actively exporting the MCM complex from the nucleus during $\mathrm{S}$ phase, like in yeast. In $A$. thaliana and Nicotiana benthamiana, MCM5 and MCM7 are in the nucleus throughout most of the cell cycle and are displaced for only a brief period during mitosis (Shultz et al., 2009). Plant ORC1 is weakly associated to chromatin (Shultz et al., 2009), compared to mammals, where ORC1 is not part of the core origin recognition complex (Ohta et al., 2003).

At the transition between M and G1 in many eukaryotes, MCMs are transported back to the nucleus to take part in another round of DNA replication licensing (Blow and Prokhorova, 1999). In animals, however, they remain inside the nucleus, and it is the inactivation of CDT1 that prevents MCM to load onto DNA again, as CDT1 is a key factor during MCM recruitment (Blow and Dutta 2005; Kerns et al., 2007; reviewed by Rizzardi and Cook 2012). CDT1 is regulated mainly by ubiquitin-targeted proteolysis in animals (a process triggered by $\mathrm{CDK} /$ cyclin activity) and by interaction with Geminin, which sequesters CDT1, avoiding the complete pre-RC re-assembly (Suchyta et al., 2015). Geminins have also been implicated in the regulation of cell proliferation and cell differentiation by interacting in a competitive way with components of the pre-RC (CDT1) or with transcription factors (Six and Hox) (del Bene et al., 2004; Luo et al., 2004). Unlike animals, plants do not seem to have a Geminin homolog, and it is not yet determined if and how CDT1 regulates MCM loading. The CDT1 partner GEM shares similarity with animal Geminins, as the competition of GEM for binding to CDT1 or to the transcription factor TTG1 might modulate the expression of the homeobox factor GLABRA (GL2) and control cell division (Caro et al., 2007). GEM is an ABA-responsive protein that has a role in seed dormancy (Mauri et al., 2016); nevertheless the function of GEM in regulating the availability of CDT1 and DNA replication licensing in plants remains to be demonstrated.

\section{Regulation of pre-RC licensing by mRNA expression profiles.}

The spatial and temporal expression patterns of the pre-RC genes have been studied in different plant species using various experimental approaches, such as in $O$. sativa (Kimura et al., 2000; Mori et al., 2005; Cho et al., 2008); Z. mays (Sabelli et al., 1996, 1999; Bastida and Puigdomenech, 2002; Witmer, 2003; Li et al., 2005; Dresselhaus et al., 2006); A. thaliana (Witmer, 2003; Collinge et al., 2004; Masuda et al., 2004; Raynaud et al., 2005; Shultz et al., 2007) and N. tabacum (Dambrauskas, 2003). The responses of pre-RC gene expression to various signals indicate that transcriptional control might exert an important level of regulation of the complex function. In addition, the data showed different expression profiles among pre-RC components suggesting the existence of various forms of the complex, possibly playing different roles during development (Raynaud et al., 2005; Dang et al., 2011). Finally, the expression of pre-RC genes in tissues with low levels of cell proliferation suggests that they are likely to perform functions outside of the complex, not related to cell division (Dresselhaus et al., 2006; Dang et al., 2011). Various studies have also identified pre-RC interactions with proteins not related to the plant cell cycle (Table 2).

Analyses of mRNA levels of pre-RC members from A. thaliana during a cell cycle round revealed a cell cycle-regulated profile, as transcript levels of pre-RC members are reduced significantly during $\mathrm{S}$ phase, especially ORC3 and CDC6 (Castellano et al., 2001; Ramos et al., 2001; Masuda et al., 2004). Later, in the transition from $\mathrm{G} 2 / \mathrm{M}$, mRNA levels of most members rise again, displaying a similar pattern (Castellano et al., 2001; Masuda et al., 2004). However, the cell cycle expression profile of pre$\mathrm{RC}$ members varies among plant species. In $N$. tabacum cell cultures, NtMCM3 expression is not confined to a cell cycle-specific phase, differently from NtCDC6, which is cell cycle regulated (Dambrauskas, 2003). In rice, MCM5 and -7 are found in high levels in the nucleus during both G1/S and G2/M phases (Shultz et al., 2009). MCM6 expression is high, but it declines during $\mathrm{S}$ phase to undetectable levels in late $\mathrm{S}$ and G2 phases in maize (Dresselhaus et al., 2006).

Possibly, the cell cycle activation of pre-RC genes transcription in G1 is mainly mediated by the RBR-E2F pathway, a major activator of the cell cycle machinery that is highly conserved in eukaryotes, including the plant kingdom, from macro- and microalgae to eudicots (Bisová and Zachleder, 2014; Desvoyes et al., 2014; Huysman et al., 
2014). The phosphorylation of RBR by the CDK-cyclinD complex is a trigger point that releases the expression of cell cycle genes that are under the control of E2F-DP, such as pre-RC members (reviewed in Scofield et al., 2014), and irreversibly commits the cell to DNA replication (Dimova and Dyson, 2005) (Figure 2). Promoters of all A. thaliana pre-RC genes, excluding AtORC5, have a putative E2F consensus binding motif (Castellano et al., 2001, 2004; Diaz-Trivino et al., 2005). It was shown that the CDTla and $O R C 2$ genes are regulated before $\mathrm{S}$ phase by E2F in $A$. thaliana (Castellano et al., 2004; Magyar et al., 2012).

The spatial and temporal mRNA localization of different members of the pre-RC machinery can be very diverse, depending on the tissue observed, and their regulation might also involve epigenetic control besides transcription factors (reviewed in Raynaud et al., 2014). For example, the function of $A$. thaliana DNA replication factor $\mathrm{C}$ was recently described in the maintenance of gene silencing through histone methylation (Liu et al., 2010). Furthermore, at the G1/S transition, histone acetylation is required for the specification and activation of replication origins (Costas et al., 2011). A new Agenet/Tudor domain protein named AIP1 (ABAP1 interacting protein 1) was described as interacting with histones, ABAP1, and the plant histone modification reader (LHP1) to regulate the expression of ABAP1 and LHP1 target genes in flower buds, such as AtCdt1b and Flower Locus T(FT), respectively (Brasil et al. 2015). In addition, intrinsic or extrinsic signals may affect plant growth, interfering with cell cycle regulation, endoreduplication, stress responses and cell death (DiazTrivino et al., 2005; reviewed in John and Qi, 2008; Magyar et al., 2012; Sabelli et al., 2013). All these processes may be part of the same machinery, directly coordinating the expression of pre-RC members.

Consistent with a role in DNA replication, mRNAs of ORCs from A. thaliana, rice and maize, as well as transcripts of AtCDC6, AtMCMs and ZmMCMs are abundant in proliferating tissues, such as root tips, lateral root development, seedlings, young leaves and flower buds (Sabelli et al., 1996; Springer et al., 2000; Castellano et al., 2001; Bastida and Puigdomenech, 2002; Masuda et al., 2004; Diaz-Trivino et al., 2005; Schreiber et al., 2006; Dang et al., 2011; Chen et al., 2013). In rice, OsORC1 and OsORC2 are strongly expressed in roots and inflorescence meristems, respectively, but there is a reduction of expression of OsORCs in tissues with low proliferative rates, leading to complete absence in mature leaves (Kimura et al., 2000; Li et al., 2005). Similarly, mRNA levels of maize ZmORCs, except for $Z m O R C 3$, are very low in mature leaves with few dividing cells, differing from the high expression levels observed in highly proliferative tissues (Witmer, 2003; Schreiber et al., 2006; Sabelli et al., 2013).

In $A$. thaliana, pre-RC members can also be found in organs with low cell division rates (Masuda et al., 2004; Diaz-Trivino et al., 2005). This expression profile outside proliferating cells could be correlated with DNA replication in endoreduplicating cells (reviewed in John and Qi, 2008). AtORCla, and not AtORC1b, is highly expressed in tissues that undergo extra endocycles of DNA replication (Diaz-Trivino et al., 2005). The two AtCDC6 genes also present different expression profiles (Masuda et al., 2004), and $A t C D C 6 a$ expression in non-dividing tissues has been associated with endoreduplication events (Castellano et al., 2001). Also, higher AtCDT1 levels are directly correlated with an increase in the number of endocycles (Castellano et al., 2004).

Alternatively, pre-RC members could also be involved in regulating processes other than licensing DNA for replication. In other eukaryotes, pre-RC proteins have been implicated in different roles, such as transcriptional regulation and heterochromatin assembly in yeast and metazoans, sister chromatin cohesion, chromosome segregation and cytokinesis, neuronal development, and centriole and centrosome copy number (Hemerly et al., 2009; reviewed in Sasaki and Gilbert, 2007). Functional data have already demonstrated that the role of pre-RC members in plants is not limited to licensing DNA for replication, but is also related to the regulation of gene expression, chromatin condensation and cell differentiation, directly influencing the growth and development of plants from embryogenesis until the senescence (discussed below - see Table 3).

Plants seem to sense many environmental conditions and adjust cell cycle progression, at least in part, by regulating the expression of pre-RC components. In this context, plant hormones have great importance by integrating signaling between organs and tissues within the plant and among other organisms, and in response to the environment (Takatsuka and Umeda, 2014). In higher plants, the TOR kinase protein integrates the auxin pathway with nutrient signals, resulting in both growth and cell division responses to the environment (Bögre et al., 2013; Henriques et al., 2014). In cell cultures, auxin has been implicated in participating in the stabilization of $E 2 F b$, compromising cells to the G1 to S phase transition (Magyar et al., 2005; Berckmans et al., 2011). Cell cycle progression is also regulated by sucrose, which stimulates progression into $\mathrm{S}$ phase and cell division by controlling cyclins and pre-RC gene expression (Masuda et al., 2004; Planchais et al., 2004, Menges et al., 2006). Recently it was suggested that methyl jasmonate contributes to inhibit the initiation of DNA replication by repression of CDC6 and CDT1 levels (Noir et al., 2013).

\section{Epigenetic mechanisms in pre-RC function.}

Although not yet well understood, animal DNA replication timing and its regulation through epigenetic mechanisms, ranging from DNA methylation to histone modifications and higher order chromatin structure, have been studied more deeply in the last years (reviewed by Casas- 


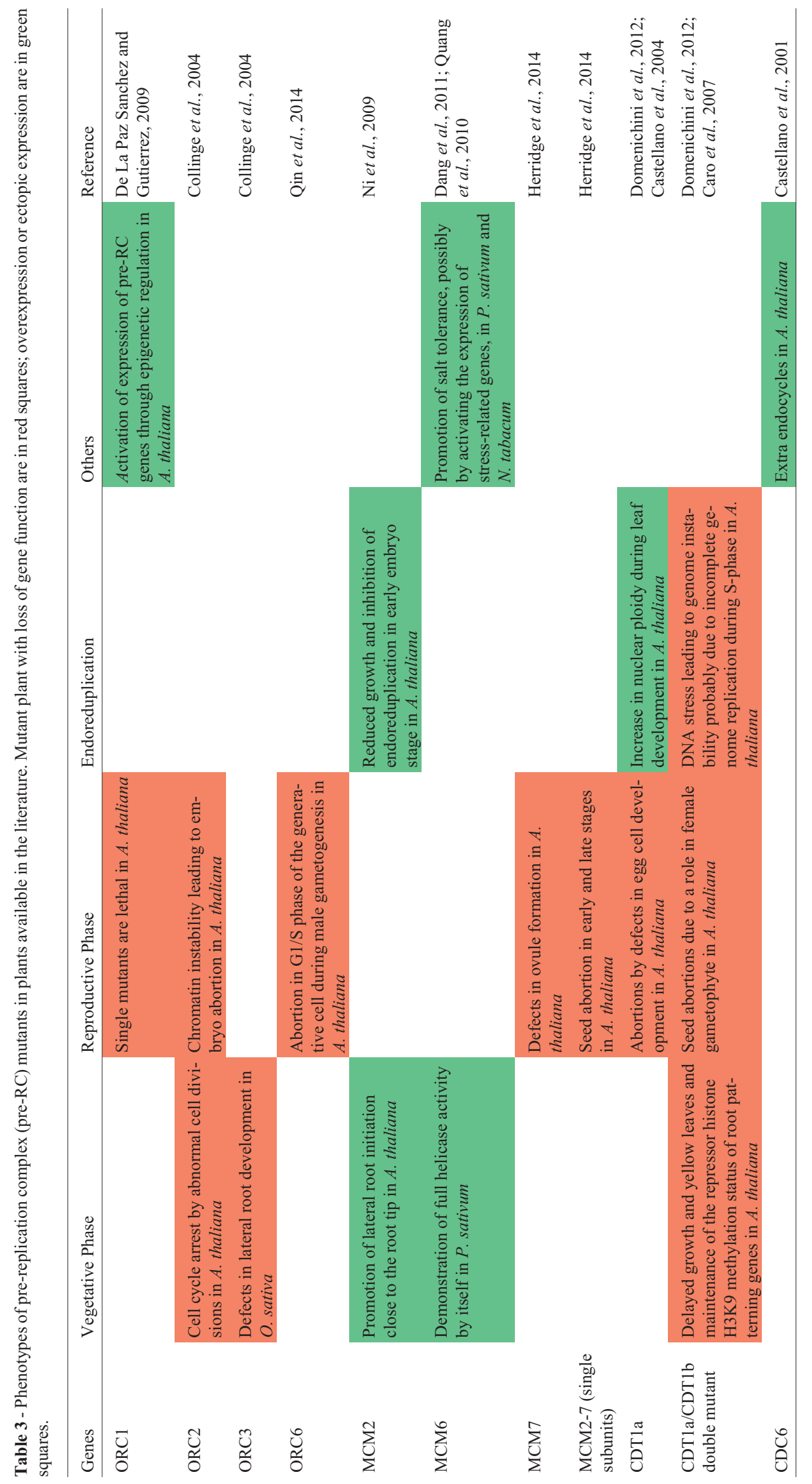


Delucchi and Cardoso, 2011). In plants, 130 epigenetic regulators have been described so far, revealing enormous diversity and contributing to the understanding of plant plasticity (Pikaard and Mittelsten Scheid, 2014). However, very little is known about epigenetic mechanisms regulating the cell cycle.

As discussed above, some epigenetic marks are enriched in DNA replication origins of A. thaliana (Costas et al., 2011), suggesting that chromatin modification proteins could be involved in specifying replication origins and/or regulating DNA replication timing in plants.

ORC1 has an interesting role in the activation of pre-RC through epigenetic regulation of gene expression. The role of BAH domains of ORC1 in transcriptional silencing has been well studied in yeast (Rusche et al., 2003), and their involvement in DNA damage was reported in metazoans (Kuo et al., 2012). In A. thaliana, the PHD domain, present in the $\mathrm{C}$-terminus of both $O R C 1$ genes, is responsible for the recognition and binding to histone $\mathrm{H} 3 \mathrm{~K} 4 \mathrm{me} 3$ residues in promoters of target genes such as MCM3, CDTI a, and ORC3 (Sanchez and Gutierrez, 2009). Moreover, the binding of ORC1 to its targets is related to the increase in $\mathrm{H} 4$ acetylation and trimethylation of H4K20 (Sanchez and Gutierrez, 2009). Recently, the crystal structure of the AtORC1b BAH-PHD cassette and its preference for the unmodified state of key amino acids when in complex with a $\mathrm{H} 3$ peptide was reported, revealing a unique "sandwiching" mode of ORC1 recognition of its targets ( $\mathrm{Li}$ et al., 2016).

The Agenet/Tudor-domain protein, AIP1, which interacts with the pre- $\mathrm{RC}$ regulator ABAP1 and with unmodified histones, regulates the expression of ABAP1 target genes such as $A t C d t 1 b$ and seems to connect DNA replication and transcription to chromatin remodeling controls during flower development (Brasil et al., 2015).

Therefore, pre-RC members, pre- $\mathrm{RC}$ regulators and epigenetic players were described as partners in regulating both transcription and replication origin specification and/or activation in plants. Transcription and replication are two cellular processes that require chromatin accessibility, however it has not yet been elucidated if and how they are integrated in plant cells. As discussed above, a high percentage of origins in A. thaliana co-localizes with the 5, end of gene units and are more concentrated in highly expressed genes (Costas et al., 2011). Hence, one question that remains to be answered is whether pre-RC proteins and their regulators, together with epigenetic mechanisms, could be, to certain extent, shared between replication licensing and transcription machineries to co-regulate these vital cellular processes.

\section{What do mutants tell us about pre-RC function?}

Functional analyses of pre-RC components were investigated in plants with modified levels of gene expression. The observed phenotypes for each mutation are sum- marized in Table 3. These studies showed that mutants in plant pre-RC genes could interfere in developmental processes either by directly affecting replication or by indirect effects on endoreduplication and heterochromatin formation (Table 3).

Complete knockout plants for $O R C$ genes cannot survive, indicating that these genes are vital for the plant to complete its life cycle (Collinge et al., 2004; Sanchez and Gutierrez, 2009; Chen et al., 2013). Constitutive expression of a specific mutation in the PHD domain of ORC $1 b$ in A. thaliana leads to the loss of the ORC1b overexpression phenotype characterized by increased cell proliferation (Sanchez and Gutierrez, 2009), revealing that PHD is essential for ORC function in DNA replication. ORC1 is not only required to form the pre-RC and to license DNA replication, but it also has a role in pre-RC activation through epigenetic regulation of gene expression (Takayama et al., 2000; Saitoh et al., 2002; Rusche et al., 2003).

In A. thaliana, the ORC2 mutants show a zygoticlethal phenotype, with abortion of embryos in the early globular state and enlarged endosperm nuclei (Collinge et al., 2004). It has been proposed that low ORC2 levels in the mutants prevent pre-RC assembly and the lack of the check point before S-phase in embryo cells; this (a) leads to many endoreduplication cycles and the enlargement of the endosperm nuclei; as well as (b) triggers cell cycle arrest, leading to abnormal divisions and chromatin instability that results in abortion of the embryo (Collinge et al., 2004).

In a developmental context, OsORC3 knockdown rice plants lack lateral roots and have a dwarf phenotype (Chen et al., 2013). A very fast differentiation of lateral root cells requires rapid cycles of cell division for tissue maintenance and development. However, in cells with lower OsORC3 availability, the G1/S phase is compromised, leading to lower proliferation levels and tissue defects (Chen et al., 2013).

AtORC6 is required for the mitosis that gives origin to the two sperm cells of the $A$. thaliana male gametophyte, and its absence causes abortion of the generative cell, with aberrant DNA content (Qin et al., 2014). proBRP4:ORC6 RNAi mutants with reduced expression of ORC6 display pollen developmental defects, and aborted generative cells have a lower DNA content, suggesting impairment at the G1/S phase (Qin et al., 2014). ORC6 acts downstream of BRP4, a TFIIB-related protein involved in regulation of the mitotic cell cycle progression during male gametogenesis (Qin et al., 2014).

AtCDT1a seems to have a specific function in female gametogenesis during embryo sac development in $A$. thaliana, while a majority of pollen grains harboring the cdt 1a mutation develop normally, possibly due to a partial redundancy with AtCDT1b in the male gametophyte (Domenichini et al., 2012). Nowack et al. (2006) first suggested that the storage of $C D K$ mRNAs in female tissues would avoid proteolysis and maintain sufficient supplies 
for cell cycle activities, proposing that pre-RC proteins may accumulate in maternal tissues. Although not yet described for other members of the pre-RC, it is possible that CDT1a accumulates in higher levels than $C D T 1 b$ at gametophyte development (Domenichini et al., 2012) due to a CDT1b plastid-targeting sequence (Raynaud et al., 2005). CDT1 and CDC6 are expressed in stomatal precursor cells, and overexpression of these genes increases the number of stomata in A. thaliana leaves (Castellano et al., 2004). In addition, simultaneous silencing of both $C d t 1$ genes shows a delay in cell cycle progression and an increase in endoreduplication (Raynaud et al., 2005). Plants with double mutation in CDTla and CDTIb show a variety of phenotypes, including: drastically reduced stature and deformed leaves; evidences of the DNA stress, probably due to incomplete genome replication during S-phase; aberrant DNA content and induction to cell death; better tolerance to DNA-damaging agents; and increased expression of genes involved in DNA repair (Domenichini et al., 2012). Moreover, CDT1 interacts with the GEM protein and may participate in the maintenance of the repressor mark histone H3K 9 methylation status on root patterning genes (Caro et al., 2007).

Disruption of $A$. thaliana MCM2 is lethal, causing plants to show problems at early embryo stage, while its overexpression in $A$. thaliana increases cell division in root meristems and decreases endoreduplication ( $\mathrm{Ni}$ et al., 2009). $\mathrm{mcm} 7$ mutants show leaky lethality in the megagametophyte (Springer et al., 1995), and its effects in embryo and endosperm development may be due the gene's primary function in the ovule (Springer et al., 2000; Holding and Springer, 2002).

AtMCM7 was the first MCM protein identified in plants, reported with the name of PROLIFERA (PRL) and with functions in reproduction and embryo development (Springer et al., 1995). Later, Herridge et al. (2014) studied all $M C M s$ mutants separately during $A$. thaliana seed development. It was observed that, in general, reduced MCM in the endosperm promotes the expression of genes involved in DNA damage response in the ATM-dependent pathway. As expected for pre-RC genes, homozygous mutants for all MCMs are lethal, but different proportions of seed abortion in early and late stages are observed when heterozygous mutants are analyzed: $m c m 2$ and $m c m 5$ have the highest rates of late abortion and $\mathrm{mcm} 3$ and $\mathrm{mcm} 4$ the lowest. The endosperm defects in mutants are generally characterized by fewer and larger nuclei compared to wild-type seeds, the absence of cellularization in endosperm, and abnormal embryo cytokinesis. Among all mutants, $m \mathrm{~cm} 7$ is the more distinct one, and its defect at an early embryo stage confirms previous data that MCM7 is required during ovule development (Herridge et al., 2014). The first evidence of a single subunit of PSMCM6 with a full helicase activity in vitro was demonstrated by Tran et al. (2010). Helicase activity, as well as an ATPase activity, have been described for AtMCM3 with greater unwinding efficiency with 5-forked DNA, and the indispensable presence of ATP and magnesium ion (Rizvi et al., 2016). All together, these data points out the difference between plant and animal MCM mechanisms of action, once multiheterodimers of MCM were reported in animals only.

Interestingly, a role of pre- $\mathrm{RC}$ on environmental responses was shown by the overexpression of PsMCM6 in $P$. sativum, which increased salinity tolerance and cold stress in an ABA-independent pathway (Dang et al., 2011). While the exact mechanism of stress tolerance is not known, the PsMCM6 characterization as $\mathrm{Zn}-\mathrm{HD}$ family member supports its role in stress tolerance (Tran et al., 2010).

Remarkably, deregulation of expression (silencing or overexpression) of the different pre-RC members show different effects on plant developmental processes, suggesting that they might have distinct roles in the pre-RC and/or might reflect their particular roles outside the complex. All together, the functional analysis data confirm that pre- $\mathrm{RC}$ genes are not only main actors in licensing DNA for replication, but that they additionally have a role in chromatin stability and as regulators of gene expression, either by interaction with transcription factors or by epigenetic pathways. These combined roles might act by integrating cell cycle progression in plants with developmental and environmental signaling.

\section{Conclusions and Perspectives}

Plants are continuously sensing the environment and modulating their development by adjusting the growth, architecture and timing of development of new organs. This means that every plant meristem might be sensing exogenous signals and integrating these with genetic controls, which leads to changes in gene expression that will finally balance cell proliferation and differentiation rates, to generate the correct plant form. An important control of the G1 to $\mathrm{S}$ transition of the cell cycle is the pre- $\mathrm{RC}$ that is assembled at replication origins (Figure 1).

The identification of pre- $\mathrm{RC}$ members in all plant species shows that this complex is conserved among eukaryotes. More importantly, the differences seen between kingdoms might reflect their divergence in strategies for cell cycle regulation, as these must be integrated and adapted to the niche, ecosystem, and the organisms peculiarities. On the other hand, the high conservation of pre$\mathrm{RC}$ components through evolution allows some of the discoveries in the plant systems to be translated to other multicellular organisms. The main discoveries on the regulation and biochemical mechanisms of DNA replication in multicellular eukaryotes have been made at the cellular level using animal systems. However, in multicellular organisms, cells belonging to different organs and tissues might respond to distinct developmental controls, that ultimately will modulate cell divisions in particular ways. 
Therefore, the facilities available to study plants as whole organisms make them a suitable model for developmental studies.

There are still very important aspects of the pre- $\mathrm{RC}$ regulation and activity that need to be elucidated in plants. The understanding of the mechanism of origin recognition and selection, and how it is integrated with transcription controls, could enlighten ideas on specific strategies of cell cycle regulation as well as how cell cycle controls respond to environmental changes, and finally, how plant plasticity is integrated with these processes. Although pre- $\mathrm{RC}$ regulators were identified and mutant studies gave insights on pre-RC functions, it is now necessary to assemble all the pieces of the puzzle to understand how cell cycle regulation is integrated with developmental and environmental signals, in order to generate adaptive responses, culminating with plant bodies adjusted to their surroundings.

\section{Acknowledgments}

We would like to thank Helkin Forero Ballesteros for preparing the illustrations. The research was supported by Fundação de Amparo à Pesquisa do Estado do Rio de Janeiro (FAPERJ), Coordenação de Aperfeiçoamento de Pessoal de Nível Superior (CAPES/COFECUB), and Conselho Nacional de Desenvolvimento Científico e Tecnológico (CNPq). JNB was supported by CNPq and by the international exchange program Science without Borders $(\mathrm{CNPq})$ for $\mathrm{PhD}$ fellowships. CNMC was supported by $\mathrm{CNPq}$ and by the international exchange program CAPES/COFECUB for $\mathrm{PhD}$ fellowships. ASH and PCGF received support as $\mathrm{CNPq}$ and FAPERJ researchers.

\section{References}

Aasland R, Gibson TJ and Stewart AF (1995) The PHD finger: Implications for chromatin-mediated transcriptional regulation. Trends Biochem Sci 20:56-59.

Aladjem MI (2007) Replication in context: Dynamic regulation of DNA replication patterns in metazoans. Nat Rev Genet 8:588-600.

Bass HW, Wear EE, Lee TJ, Hoffman GG, Gumber HK, Allen GC, Thompson WF and Hanley-Bowdoin L (2014) A maize root tip system to study DNA replication programmes in somatic and endocycling nuclei during plant development. J Exp Bot 65:2747-2756.

Bastida M and Puigdomenech P (2002) Specific expression of ZmPRL, the maize homolog of MCM7, during early embryogenesis. Plant Sci 162:97-106.

Bell SP (2002) The origin recognition complex: From simple origins to complex functions. Genes Dev 16:659-672.

Bell SP and Dutta A (2002) DNA replication in eukaryotic cells. Annu Rev Biochem 71:333-374.

Berckmans B, Vassileva V, Schmid SP, Maes S, Parizot B, Naramoto S, Magyar Z, Alvim Kamei CL, Koncz C, Bögre L, et al. (2011) Auxin-dependent cell cycle reactivation through transcriptional regulation of Arabidopsis E2Fa by lateral organ boundary proteins. Plant Cell 23:3671-3683.
Bisová K and Zachleder V (2014) Cell-cycle regulation in green algae dividing by multiple fission. J Exp Bot 65:2585-2602.

Blow JJ and Dutta A (2005) Preventing re-replication of chromosomal DNA. Nat Rev Mol Cell Biol 6:476-486.

Blow JJ and Prokhorova TA (1999) Saying a firm "no" to DNA re-replication. Nat Cell Biol 1:E175-E177.

Blumenthal AB, Kriegstein HJ and Hogness DS (1974) The units of DNA replication in Drosophila melanogaster chromosomes. Cold Spring Harb Symp Quant Biol 38:205-223.

Bögre L, Henriques R and Magyar Z (2013) TOR tour to auxin. EMBO J 32:1069-1071.

Boniotti MB and Griffith ME (2002) "Cross-talk" between cell division cycle and development in plants. Plant Cell 14:11-16.

Brasil JN, Cabral LM, Eloy NB, Primo LMF, Barroso-Neto IT, Grangeiro LPP, Gonzalez N, Inzé D, Ferreira PCG and Hemerly AS (2015) AIP1 is a novel Agenet/Tudor domain protein from Arabidopsis that interacts with regulators of DNA replication, transcription and chromatin remodeling. BMC Plant Biol 15:270.

Brukhin V and Morozova N (2011) Plant growth and development - Basic knowledge and current views. Mathemat Model Nat Phen 6:1-53.

Bryant JA (2011) Replication of nuclear DNA. Ann Bot 107:106.

Bryant JA and Aves SJ (2011) Initiation of DNA replication: Functional and evolutionary aspects. Ann Bot 107:11191126.

Callebaut IY, Courvalin J and Mornon J (1999) The BAH (bromo-adjacent homology) domain: A link between DNA methylation, replication and transcriptional regulation. FEBS Lett 446:189-193.

Caro E, Castellano MM and Gutierrez C (2007) A chromatin link that couples cell division to root epidermis patterning in Arabidopsis. Nature 447:213-217.

Casas-Delucchi CS and Cardoso MC (2011) Epigenetic control of DNA replication dynamics in mammals. Nucleus 2:370382.

Castellano MM, Carlos J, Ramirez-Parra E, Brown S and Gutierrez C (2001) Expression and stability of Arabidopsis CDC6 are associated with endoreplication. Plant Cell 13:26712686.

Castellano M, Boniotti M, Caro E, Schnittger A and Gutierrez C (2004) DNA replication licensing affects cell proliferation or rndoreplication in a cell type-specific manner. Plant Cell 16:2380-2393.

Cayrou C, Coulombe P, Vigneron A, Stanojcic S, Ganier O, Peiffer I, Rivals E, Puy A, Laurent-Chabalier S, Desprat R, et al. (2011) Genome-scale analysis of metazoan replication origins reveals their organization in specific but flexible sites defined by conserved features. Genome Res 21:14381449.

Chang IF, Curran A, Woolsey R, Quilici D, Cushman JC, Mittler R, Harmon A and Harper JF (2009) Proteomic profiling of tandem affinity purified 14-3-3 protein complexes in Arabidopsis thaliana. Proteomics 9:2967-2985.

Chen X, Shi J, Hao X, Liu H, Shi J, Wu Y, Wu Z, Chen M, Wu P and Mao C (2013) OsORC3 is required for lateral root development in rice. Plant J 74:339-350.

Cho JH, Kim HB, Kim H-S and Choi S-B (2008) Identification and characterization of a rice MCM2 homologue required for DNA replication. BMB Rep 41:581-586. 
Collinge MA, Spillane C, Köhler C, Gheyselinck J and Grossniklaus U (2004) Genetic interaction of an Origin Recognition Complex Subunit and the Polycomb group gene MEDEA during seed development. Plant Cell 16:10351046.

Costas C, Sanchez M de P, Stroud H, Yu Y, Oliveros C, Feng S, Benguria A, López-Vidriero I, Zhang X, Solano R, et al. (2011) Genome-wide mapping of Arabidopsis origins of DNA replication and their associated epigenetic marks. Nat Struct Mol Biol 18:395-400.

Cunningham EL and Berger JM (2005) Unraveling the early steps of prokaryotic replication. Curr Opin Struct Biol 15:68-76.

Dambrauskas G (2003) Genes encoding two essential DNA replication activation proteins, $\mathrm{Cdc} 6$ and $\mathrm{Mcm} 3$, exhibit very different patterns of expression in the tobacco BY-2 cell cycle. J Exp Bot 54:699-706.

Dang HQ, Tran NQ, Tuteja R and Tuteja N (2011) Promoter of a salinity and cold stress-induced MCM6 DNA helicase from pea. Plant Signal Behav 6:1006-1008.

del Bene F, Tessmar-Raible K and Wittbrodt J (2004) Direct interaction of geminin and Six3 in eye development. Nature 427:745-749.

Desvoyes B, De Mendoza A, Ruiz-Trillo I and Gutierrez C (2014) Novel roles of plant RETINOBLASTOMA-RELATED (RBR) protein in cell proliferation and asymmetric cell division. J Exp Bot 65:2657-2666.

Dhar SK, Delmolino L and Dutta A (2001) Architecture of the human origin recognition complex. J Biol Chem 276:2906729071.

Diaz-Trivino S, del Mar Castellano M, Sanchez M de P, Ramirez-Parra E, Desvoyes B and Gutierrez C (2005) The genes encoding Arabidopsis ORC subunits are E2F targets and the two ORC1 genes are differently expressed in proliferating and endoreplicating cells. Nucleic Acids Res 33:5404-5414.

Dimova DK and Dyson NJ (2005) The E2F transcriptional network: Old acquaintances with new faces. Oncogene 24:2810-2826.

Domenichini S, Benhamed M, De Jaeger G, Van De Slijke E, Blanchet S, Bourge M, De Veylder L, Bergounioux C and Raynaud C (2012) Evidence for a role of Arabidopsis CDT1 proteins in gametophyte development and maintenance of genome integrity. Plant Cell 24:2779-2791.

Dorn ES and Cook JG (2011) Nucleosomes in the neighborhood: New roles for chromatin modifications in replication origin control. Epigenetics 6:552-559.

Dresselhaus T, Srilunchang K-O, Leljak-Levanic D, Schreiber DN and Garg P (2006) The fertilization-induced DNA replication factor MCM6 of maize shuttles between cytoplasm and nucleus, and is essential for plant growth and development Plant Physiol 140:512-527.

Errico A, Deshmukh K, Tanaka Y, Pozniakovsky A and Hunt T (2010) Identification of substrates for cyclin dependent kinases. Adv Enzyme Regul 50:375-399.

Gaudier M, Schuwirth BS, Westcott SL and Wigley DB (2007) Structural basis of DNA replication origin recognition by an ORC protein. Science 317:1213-1216.

Gavin KA, Hidaka M and Stillman B (1995) Conserved initiator proteins in eukaryotes. Science 270:1667-1671.

Grime JP and Mowfforth MA (1982) Variation in genome size An ecological interpretation. Nature 299:151-153.
Henriques R, Bögre L, Horváth B and Magyar Z (2014) Balancing act: Matching growth with environment by the TOR signalling pathway. J Exp Bot 65:2691-2701.

Hemerly AS, Prasanth SG, Siddiqui K and Stillman B (2009) Orc1 controls centriole and centrosome copy number in human cells. Science 323:789-793.

Herridge RP, Day RC and Macknight RC (2014) The role of the MCM2-7 helicase complex during Arabidopsis seed development. Plant Mol Biol 86:69-84.

Hiratani I, Takebayashi SI, Lu J and Gilbert DM (2009) Replication timing and transcriptional control: Beyond cause and effect-part II. Curr Opin Genet Dev 19:142-149.

Holding DR and Springer PS (2002) The Arabidopsis gene PROLIFERA is required for proper cytokinesis during seed development. Planta 214:373-382.

Huang X, Springer PS and Kaloshian I (2003) Expression of the Arabidopsis MCM gene PROLIFERA during root-knot and cyst Nematode infection. Phytopathology 93:35-41.

Huysman MJJ, Vyverman W and De Veylder L (2014) Molecular regulation of the diatome cell cycle. J Exp Bot 65:25732584.

Inzé D and De Veylder L (2006) Cell cycle regulation in plant development. Annu Rev Genet 40:77-105.

Jackson AL, Pahl PM, Harrison K, Rosamond J and Sclafani RA (1993) Cell cycle regulation of the yeast $\mathrm{Cdc} 7$ protein kinase by association with the Dbf4 protein. Mol Cell Biol 13:2899-2908.

John PC and Qi R (2008) Cell division and endoreduplication: Doubtful engines of vegetative growth.Trends Plant Sc.13:121-127.

Kearsey SE and Cotterill S (2003) Enigmatic variations: Divergent modes of regulating eukaryotic DNA replication. Mol Cell 12:1067-1075.

Kerns SL, Torke SJ, Benjamin JM and McGarry TJ (2007) Geminin prevents rereplication during Xenopus development. J Biol Chem 282:5514-5521.

Kim DY, Scalf M, Smith LM and Vierstra RD (2013) Advanced proteomic analyses yield a deep catalog of ubiquitylation targets in Arabidopsis. Plant Cell 25:1523-1540.

Kimura S, Ishibashi T, Hatanaka M, Sakakibara Y, Hashimoto J and Sakaguchi K (2000) Molecular cloning and characterization of a plant homologue of the origin recognition complex 1 (ORC1). Plant Sci 158:33-39.

Kuo AJ, Song J, Cheung P, Ishibe-Murakami S, Yamazoe S, Chen JK, Patel DJ and Gozani O (2012) The BAH domain of ORC1 links H4K20me2 to DNA replication licensing and Meier-Gorlin syndrome. Nature 484:115-119.

Lamesch P, Berardini TZ, Li D, Swarbreck D, Wilks C, Sasidharan R, Muller R, Dreher K, Alexander DL, Garcia-Hernandez M, et al. (2012) The Arabidopsis Information Resource (TAIR): Improved gene annotation and new tools. Nucleic Acids Res 40:1202-1210.

Latrasse D, Benhamed M, Henry Y, Herridge S, Kim W, Zhou D-X and Delarue M (2008) The MYST histone acetyltransferases are essential for gametophyte development in Arabidopsis. BMC Plant Biol 8:121.

Lee HO, Davidson JM and Duronio RJ (2009) Endoreplication: Polyploidy with purpose. Genes Dev 23:2461-2477.

Li KG, Yang JS, Attia K, Su W, He GM and Qian XY (2005) Cloning and characterization of OsORC2, a new member of rice origin recognition complex. Biotech Lett 27:1355-1359. 
Li S, Yang Z, Du X, Liu R, Wilkinson AW, Gozani O, Jacobsen SE, Patel DJ and Du J (2016) Structural basis for the unique multivalent readout of unmodified $\mathrm{H} 3$ tail by Arabidopsis ORC1b BAH-PHD cassette. Structure 24:486-494.

Liu Q, Wang J, Miki D, Xia R, Yu W, He J, Zheng Z, Zhu JK and Gong Z (2010) DNA replication factor C1 mediates genomic stability and transcriptional gene silencing in Arabidopsis. Plant Cell 22:2336-2352.

Luo L, Yang X, Takihara Y, Knoetgen H and Kessel M (2004) The cell-cycle regulator geminin inhibits Hox function through direct and polycomb-mediated interactions. Nature 427:749-753.

Magyar Z, De Veylder L, Atanassova A, Bakó L, Inzé D and Bögre L (2005) The role of the Arabidopsis E2FB transcription factor in regulating auxin-dependent cell division. Plant Cell 17:2527-2541.

Magyar Z, Horváth B, Khan S, Mohammed B, Henriques R, De Veylder L, Bakó L, Scheres B and Bögre L (2012) Arabidopsis E2FA stimulates proliferation and endocycle separately through RBR-bound and RBR-free complexes. EMBO J 31:1480-1493.

Masai H, You Z and Arai K (2005) Control of DNA replication: Regulation and activation of eukaryotic replicative helicase, MCM. IUBMB Life 57:323-335.

Masuda HP, Ramos GBA, de Almeida-Engler J, Cabral LM, Coqueiro VM, Macrini CMT, Ferreira PCG and Hemerly AS (2004) Genome based identification and analysis of the pre-replicative complex of Arabidopsis thaliana. FEBS Lett 574:192-202.

Masuda HP, Cabral LM, De Veylder L, Tanurdzic M, de Almeida Engler J, Geelen D, Inzé D, Martienssen RA, Ferreira PCG and Hemerly AS (2008) ABAP1 is a novel plant Armadillo BTB protein involved in DNA replication and transcription. EMBO J 27:2746-2756.

Mauri N, Fernández-Marcos M, Costas C, Desvoyes B, Pichel A, Caro E and Gutierrez C (2016) GEM, a member of the GRAM domain family of proteins, is part of the ABA signaling pathway. Sci Rep 6:22660.

Mechali M, Yoshida K, Coulombe P and Pasero P (2013) Genetic and epigenetic determinants of DNA replication origins, position and activation. Curr Opin Genet Dev 23:124-131.

Menges M, Samland AK, Planchais S and Murray JA (2006) The D-type cyclin CYCD3:1 is limiting for the G1-to-S-phase transition in Arabidopsis. Plant Cell 18:893-906.

Mimura S, Seki T, Tanaka S and Diffley JF (2004) Phosphorylation-dependent binding of mitotic cyclins to Cdc6 contributes to DNA replication control. Nature 431:1118-1123.

Mori Y, Yamamoto T, Sakaguchi N, Ishibashi T, Furukawa T, Kadota Y, Kuchitsu K, Hashimoto J, Kimura S and Sakaguchi $\mathrm{K}$ (2005) Characterization of the origin recognition complex (ORC) from a higher plant, rice (Oryza sativa L.). Gene 353:23-30.

Ni DA, Sozzani R, Blanchet S, Domenichini S, Reuzeau C, Cella R, Bergounioux C and Raynaud C (2009) The Arabidopsis MCM2 gene is essential to embryo development and its over-expression alters root meristem function. New Phytol 184:311-322.

Nieduszynski CA, Knox Y and Donaldson AD (2006) Genomewide identification of replication origins in yeast by comparative genomics. Genes Dev 20:1874-1879.
Noir S, Bömer M, Takahashi N, Ishida T, Tsui T-L, Balbi V, Shanahan H, Sugimoto K and Devoto A (2013) Jasmonate controls leaf growth by repressing cell proliferation and the onset of endoreduplication while maintaining a potential stand-by mode. Plant Physiol 161:1930-1951.

Nowack MK, Grini PE, Jakoby MJ, Lafos M, Koncz C and Schnittger A (2006) A positive signal from the fertilization of the egg cell sets off endosperm proliferation in angiosperm embryo- genesis. Nat Genet 38:63-67.

Ohta S, Tatsumi Y, Fujita M, Tsurimoto T and Obuse C (2003) The ORC1 cycle in human cells: II dynamic changes in the human ORC complex during the cell cycle. J Biol Chem 278:41535-41540.

Pak DTS, Pflumm M, Chesnokov I, Huang DW, Kellum R, Marr J, Romanowski P and Botchan MR (1997) Association of the origin recognition complex with heterochromatin and HP1 in higher eukaryotes. Cell 91:311-323.

Pikaard CS and Mittelsten Scheid O (2014) Epigenetic regulation in plants. Cold Spring Harb Perspect Biol 6:a019315.

Planchais S, Samland AK and Murray JA (2004) Differential stability of Arabidopsis D-type cyclins: CYCD3:1 is a highly unstable protein degraded by a proteasome-dependent mechanism. Plant J 38:616-625.

Pusch S, Harashima H and Schnittger A (2012) Identification of kinase substrates by bimolecular complementation assays. Plant J 70:348-356.

Qin Z, Zhang X, Zhang X, Xin W, Li J and Hu Y (2014) The Arabidopsis transcription factor IIB-related protein BRP4 is involved in the regulation of mitotic cell-cycle progression during male gametogenesis. J Exp Bot 65:2521-2531.

Ramos GBA, Engler JDA, Ferreira PCG and Hemerly AS (2001) DNA replication in plants: Characterization of a cdc6 homologue from Arabidopsis thaliana. J Exp Bot 52:2239-2240.

Raynaud C, Perennes C, Reuzeau C, Catrice O, Brown S and Bergounioux C (2005) Cell and plastid division are coordinated through the prereplication factor AtCDT1. Proc Natl Acad Sci U S A 102:8216-8221.

Raynaud C, Mallory AC, Latrasse D, Jégu T, Bruggeman Q, Delarue M, Bergounioux C and Benhamed M (2014) Chromatin meets the cell cycle. J Exp Bot 65:2677-2689.

Rizvi I, Choudhury NR and Tuteja N (2016) Arabidopsis thaliana MCM3 single subunit of MCM2-7 complex functions as 3' to 5' DNA helicase. Protoplasma 253:467-475.

Rizzardi LF, Dorn ES, Strahl BD and Cook JG (2012) DNA replication origin function is promoted by $\mathrm{H} 3 \mathrm{~K} 4 \mathrm{di}$-methylation in Saccharomyces cerevisiae. Genetics 192:371-384.

Rizzardi LF and Cook JG (2012) Flipping the switch from G1 to S phase with e3 ubiquitin ligases. Genes Cancer 3:634-648.

Rusche LN, Kirchmaier AL and Rine J (2003) The establishment, inheritance, and function of silenced chromatin in Saccharomyces cerevisiae. Annu Rev Biochem 72:481-516.

Sabelli PA, Burgess SR, Kush AK, Young MR and Shewry PR (1996) cDNA cloning and characterisation of a maize homologue of the MCM proteins required for the initiation of DNA replication. Mol Gen Genet 252:125-136.

Sabelli PA, Parker JS and Barlow PW (1999) cDNA and promoter sequences for MCM3 homologues from maize, and protein localization in cycling cells. J Exp Bot 50:1315-1322.

Sabelli PA, Liu Y, Dante RA, Lizarraga LE, Nguyen HN, Brown SW, Klingler JP, Yu J, LaBrant E, Layton TM, et al. (2013) Control of cell proliferation, endoreduplication, cell size, 
and cell death by the retinoblastoma-related pathway in maize endosperm. Proc Natl Acad Sci U S A 110:E1827E1836.

Saitoh Y, Miyagi S, Ariga H and Tsutsumi K (2002) Functional domains involved in the interaction between Orc1 and transcriptional repressor AlF-C that bind to an origin/promoter of the rat aldolase B gene. Nucleic Acids Res 30:5205-5212.

Sanchez M de P and Gutierrez C (2009) Arabidopsis ORC1 is a PHD-containing H3K4me3 effector that regulates transcription. Proc Natl Acad Sci U S A 106:2065-2070.

Sasaki T and Gilbert DM (2007) The many faces of the origin recognition complex. Curr Opin Cell Biol 19:337-343.

Scheres B (2007) Stem-cell niches: Nursery rhymes across kingdoms. Nat Rev Mol Cell Biol 8:345-354.

Schreiber DN, Dresselhaus T, Srilunchang K and Leljak-levanic D (2006) The fertilization-induced DNA replication factor MCM6 of maize shuttles between cytoplasm and nucleus, and is essential for plant growth and development. Plant Physiol 140:512-527.

Scofield S, Jones A and Murray JAH (2014) The plant cell cycle in context. J Exp Bot 65:2557-2562.

Shultz RW, Tatineni VM, Hanley-Bowdoin L and Thompson WF (2007) Genome-wide analysis of the core DNA replication machinery in the higher plants Arabidopsis and rice. Plant Physiol 144:1697-1714.

Shultz RW, Lee T-J, Allen GC, Thompson WF and HanleyBowdoin L (2009) Dynamic localization of the DNA replication proteins MCM5 and MCM7 in plants. Plant Physiol 150:658-669.

Springer P, McCombie W, Sundaresan V and Martienssen R (1995) Gene trap tagging of PROLIFERA, an essential MCM2-3-5-like gene in Arabidopsis. Science 268:877-880.

Springer PS, Holding DR, Groover A, Yordan C and Martienssen RA (2000) The essential Mcm7 protein PROLIFERA is localized to the nucleus of dividing cells during the G1 phase and is required maternally for early Arabidopsis development. Development 127:1815-1822.

Stevens R, Mariconti L, Rossignol P, Perennes C, Cella R and Bergounioux C (2002) Two E2F sites in the Arabidopsis MCM3 promoter have different roles in cell cycle activation and meristematic expression. J Biol Chem 277:3297832984.

Suchyta M, Miotto B and McGarry T (2015) An inactive Geminin mutant that binds Cdt1. Genes 6:252-266.
Sugimoto-Shirasu K and Roberts K (2003) Big it up: Endoreduplicaton and the control of cell size. Curr Opin Plant Biol 6:544-553.

Takatsuka H and Umeda M (2014) Hormonal control of cell division and elongation along differentiation trajectories in roots. J Exp Bot 65:2633-2643.

Takayama MA, Taira T, Tamai K, Iguchi-Ariga SMM and Ariga H (2000) ORC1 interacts with c-Myc to inhibit E-boxdependent transcription by abrogating c-Myc-SNF5/INI1 interaction. Genes Cells 5:481-490.

Tan D, Lv Q, Chen X, Shi J, Ren M, Wu P and Mao C (2013) Interactions among rice ORC subunits. Plant Signal Behav 8:8-10.

Tardat M, Brustel J, Kirsh O, Lefevbre C, Callanan M, Sardet C and Julien E (2010) The histone H4 Lys 20 methyltransferase PR-Set7 regulates replication origins in mammalian cells. Nat Cell Biol 12:1086-1093.

Tran NQ, Dang HQ, Tuteja R and Tuteja N (2010) A single subunit MCM6 from pea forms homohexamer and functions as DNA helicase. Plant Mol Biol 74:327-336.

Tuteja N, Tran NQ, Dang HQ and Tuteja R (2011) Plant MCM proteins: Role in DNA replication and beyond. Plant Mol Biol 77:537-545.

Van Leene J, Hollunder J, Eeckhout D, Persiau G, Van De Slijke E, Stals H, Van Isterdael G, Verkest A, Neirynck S, Buffel Y, et al. (2010) Targeted interactomics reveals a complex core cell cycle machinery in Arabidopsis thaliana. Mol Syst Biol 6:397.

Veylder LD, Joubès J and Inzé D (2003) Plant cell cycle transitions. Curr Opin Plant Biol 6:536-543.

Vorobyeva NE, Mazina MU, Golovnin AK, Kopytova DV, Gurskiy DY, Nabirochkina EN, Georgieva SG, Georgiev PG and Krasnov AN (2013) Insulator protein $\mathrm{Su}(\mathrm{Hw})$ recruits SAGA and Brahma complexes and constitutes part of origin recognition complex-binding sites in the Drosophila genome. Nucleic Acids Res 41:5717-5730.

Witmer X (2003) Putative subunits of the maize origin of replication recognition complex ZmORC1-ZmORC5. Nucleic Acids Res 31619-31628.

Associate Editor: Marcia Pinheiro Margis

License information: This is an open-access article distributed under the terms of the Creative Commons Attribution License (type CC-BY), which permits unrestricted use, distribution and reproduction in any medium, provided the original article is properly cited. 